\title{
Nonobstructive Mucosal Diaphragms of the Pyloric Antrum in Adults: Report of Two Cases
}

Two cases of mucosal diaphragm of the gastric antrum, a rare congenital anomaly of the stomach (1) are presented here. In adults, the diaphragm is a thin perforated web consisting of gastric mucosa and submucosa perpendicular to a long axis of the pyloric antrum, $1.5-7.0 \mathrm{~cm}$ proximal to the pylorus $(2-4)$.

Case 1. A 27-year-old edentulous male was referred for evaluation of dyspepsia. Gastroscopy revealed a $4 \mathrm{~mm}$ thick ring membrane with a $12 \mathrm{~mm}$ triangular central opening in the pyloric antrum, about $2 \mathrm{~cm}$ proximal to the pylorus (Figure 1). Biopsy showed chronic superficial gastritis, and the radiograph showed a short, fixed, concentric narrowing of the gastric antrum (Figure 2).

Case 2. A 70-year-old edentulous female was admitted with postprandial epigastric pain, nausea, and vomiting. A thin, linear filling defect in the pyloric antrum was seen on the radiograph. Upper gastrointestinal endoscopy showed a semicircular web covered by normal mucosa in the distal esophagus, a small hiatal hernia, and 2 $\mathrm{mm}$ thick diaphragm with an oval central opening of $18 \mathrm{~mm}$ in the pyloric antrum about $3 \mathrm{~cm}$ proximal to the pylorus. Biopsy showed profound chronic gastritis.

When the inner diameter of this type of diaphragm in the antrum exceeds $1 \mathrm{~cm}$, clinical symptoms are usually lacking (3). However, in some patients with large openings, the short-lived dyspeptic or even obstructive symptoms may be caused by gastritis involving the diaphragmatic mucosa and giving rise to edema of the opening (2), especially when accompanied by impaction of poorly masticated food in an edentulous patient. The association of an antral diaphragm with a mucous web in the distal esophagus has been previously described (3).

\section{T. Sikorski}

Endoscopy Unit, Seventh Department of Internal Medicine Wolski Hospital, Warsaw, Poland

\section{References}

1 Rowling JT: The prepyloric septum: a rare anomaly. Br. J. Surg. 1959; 47: 162-166.

2 Sames CP: A case of partial atresia of the pyloric antrum due to a mucosal diaphragm of doubtful origin. Br. J. Surg. 1949; 37: 244246.

3 Ghahremani GG: Nonobstructive mucosal diaphragms or rings of the gastric antrum in adults. Am. J. Roentgenol. 1974; 121: 236247.

4 Clements JL, Jinkins JR, Torres WE, et al.: Antral mucosal diaphragms in adults. Am. J. Roentgenol. 1979; 133: 1105-1111.

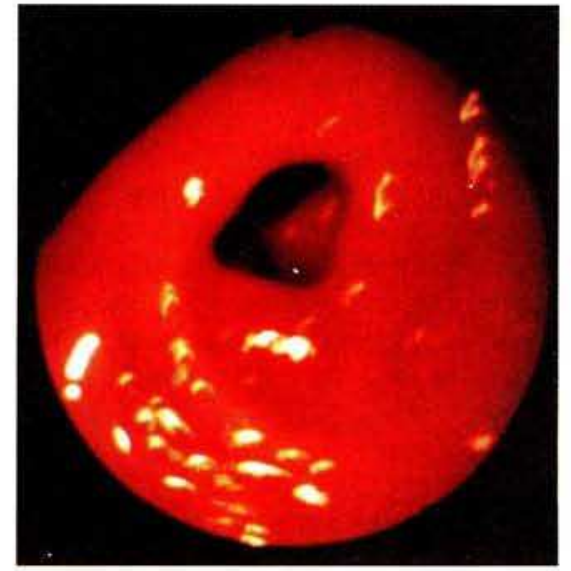

Figure 1:

Endoscopic view of a mucosal diaphragm in the antrum, with a triangular opening through which the pylorus is seen.

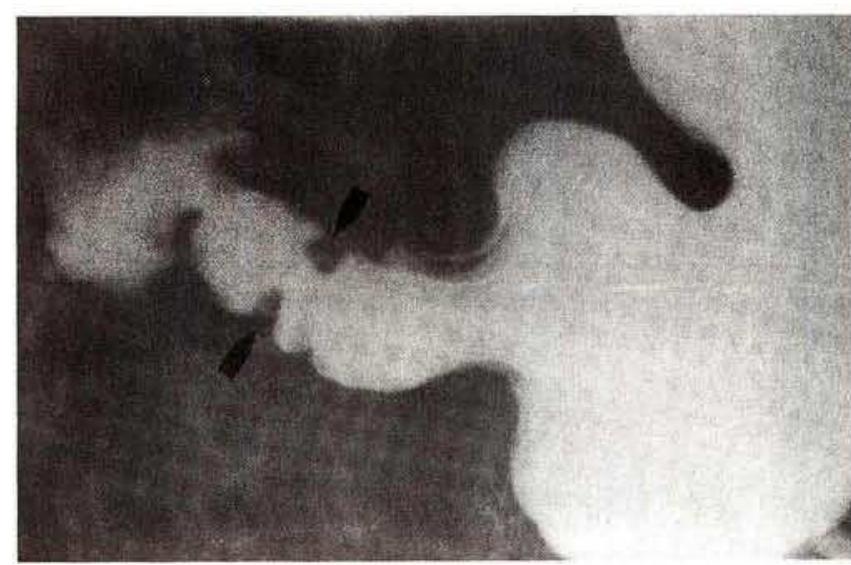

Figure 2: Radiograph of the stomach, showing a short, concentric, ring-like narrowing of the distal antrum about $2 \mathrm{~cm}$ proximal to the pylorus (arrows).

Corresponding Author

T. Sikorski, M.D.

Endoscopy Unit

Seventh Department of Internal Medicine

Wolski Hospital

17 Kasprzaka Street

01-211 Warsaw

Poland 